\title{
Differential Ability of Human Cutaneous Nociceptors to Signal Mechanical Pain and to Produce Vasodilatation
}

\author{
Martin Koltzenburg' and Hermann O. Handwerker ${ }^{2}$

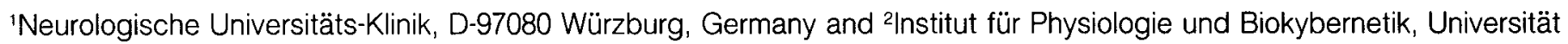 \\ Erlangen-Nürnberg, D-91054 Erlangen, Germany
}

We investigated the ability of human nociceptive primary afferent neurons to encode mechanical pain and to produce vasodilatation. Pain was induced by shooting a light metal cylinder $(0.3 \mathrm{~g})$ at different velocities $(6-18 \mathrm{~m} / \mathrm{sec})$ perpendicularly against the hairy skin of the hand. When single impact stimuli were applied, monotonically increasing stlmulus-response functions were obtained in 10 psychophysical experiments using magnitude estimation techniques. In 35 microneurographic experiments nine unmyelinated afferents were recorded from the superficial radial nerve. All units responded readily to impact stimulation even at stimulus intensities that were not rated as painful. However, there was a close linear correlation between the number of action potentials evoked from the nociceptors and the psychophysical magnitude estimates of the perceived sensation or the stimulus intensity. This was also reflected by a corresponding increase of neurogenic vasodilatation. While two thin myelinated afferents displayed qualitatively similar responses 12 low-threshold mechanosensitive afferents (4 rapidly adapting, 5 slowly adapting type I, 3 slowly adapting type II) failed to encode the intensity of the applied impact force and often became desensitized. This indicates that the total number of action potentials is the determinant of the magnitude of mechanical pain and the associated vasodilatation following single brief stimuli.

By contrast, the close correlation between nociceptor activity and sensation changed when trains of mechanical impact stimuli (five stimuli of constant intensity, intratrain frequency of $1 / 32$ to $2 \mathrm{~Hz}$ ) were applied. Magnitude estimates of pain intensity were frequency dependent and stimuli with short interstimulus intervals were perceived as more painful than those delivered with long intervals. However, the total number of action potentials evoked from $\mathrm{C}$-fibers was higher at longer interstimulus intervals than shorter intervals, thus yielding a negative correlation between the magnitude estimates of the perceived painful sensation and the number of action potentials elicited from nociceptive afferents. This suggests that temporal summation of the nociceptive discharge at central neurons becomes increasingly more important for the sensory discriminative experience of pain evoked by repetitive stimulation.

Received Jan. 4, 1993; revised Aug. 9, 1993; accepted Sept. 9, 1993.

We thank Dr. Lothar Kohllöffel for designing the mechanical stimulator, Dr. Clemens Forster for supplying the software for the spike analysis, and Karl Burian for his artwork. This work was supported by the Sonderforschungsbereich 353 of the Deutsche Forschungsgemeinschaft and the Marohn Stiftung.

Correspondence should be addressed to Martin Koltzenburg, Neurologische Universitäts-Klinik, Josef-Schneider-Strasse 11, D-97800 Würzbury, Germany.

Copyright (C) 1994 Society for Neuroscience $0270-6474 / 94 / 141756-10 \$ 05.00 / 0$
We conclude that human nociceptive C-fibers signal brief noxious mechanical stimuli by the total number of action potentials evoked during a short period of time. However, with repetitive stimulation the total number of action potentials evoked from nociceptors is less important for evoking pain and temporal summation of the nociceptive primary afferent discharge becomes the crucial factor for signaling the magnitude of sensation.

IKey words: microneurography, low-threshold mechanoreceptors, hyperalgesia, central sensitization, windup, flare, neurogenic vasodilatation]

A central problem in the study of sensory systems is how primary afferent activity and its processing by higher-order neurons relate to perception (Willis and Coggeshall, 1991). In the somatosensory system the function of central pathways mediating tactile events is thought to conserve the presentation of a stimulus dictated by the peripheral sensory apparatus (Mountcastle, 1984; Kandel and Jessell, 1991). This view has also been adopted to explain acute stimulus induced pains. It has been found that the discharge of nociceptive primary afferents encodes many aspects of the sensory discriminative component of acute stimulus-induced pain (Campbell et al., 1989). Such close correlation has been repeatedly found when human psychophysical responses to noxious heat stimuli were compared with the receptive propertics of nociccptive afferents recorded from ancsthetized monkey (Meyer and Campbell, 1981; LaMotte et al., 1983; Robinson et al., 1983) or alert humans (Gybels et al., 1979; LaMotte et al., 1982; Torebjörk et al., 1984). These studies have also determined that the increased pain perception following tissue injuries, notably mild burns, can be explained by the corresponding change of the stimulus-response functions of nociceplive afferents (Meyer and Campbell, 1981; LaMotte et al., 1982, 1992; Torebjörk et al., 1984). However, it is unclear whether the concept that has been developed for brief heat pain stimuli applies universally to all other modalities of pain stimuli.

Other studies have also noted important discrepancies between the discharge pattern of nociceptors and the corresponding sensations. Human nociceptive afferents are often vigorously activated by mechanical stimuli that are not rated as painful (Gybels et al., 1979; Van Hees and Gybels, 1981). Moreover, application of a constant level of noxious pressure over several minutes results in the gradual buildup of the pain rating, and although some fibers discharge at low intensity when such stimuli are applied outside the receptive field (Reeh et al., 1987), the discharge rate of most nociceptors actually decreases significantly (Adriaensen et al., 1984a; Handwerker et al., 1987).

This suggests that the discharge rate of nociceptors is not 
always a good predictor for the perception of experimentally induced pain and emphasizes the importance of central nervous mechanisms of nociceptive processing for the consciously perceived magnitude of sensations. One factor that could account for the differential relation of nociceptor discharge and pain sensation is the coactivation of non-nociceptive afferents. While noxious thermal stimuli would predominantly activate nociceptive afferents, noxious mechanical stimuli will also excite sensitive mechanoreceptors that are known to interact with the central processing of nociceptive inputs (Melzack and Wall, 1965; Handwerker et al., 1975). Therefore, it remains unclear whether this discrepancy between the nociceptor discharge and pain magnitude is due to inherent properties of thermal or mechanical stimulus energies or whether it is the consequence of the different stimulus duration. The knowledge of the relative importance of peripheral and central determinants of mechanical pain in normal tissue will also be important for the understanding of the increased sensitivity to mechanical stimuli that develops in injured skin (LaMotte et al., 1991; Koltzenburg et al., 1992).

Apart from signaling nociceptive events, unmyelinated and thin myelinated primary afferents have an efferent function. Excitation of cutaneous nociceptors produces a vasodilatation that spreads around a focal noxious stimulus (Chahl, 1988; Lynn, 1988; Szolcsányi, 1988; Lisney and Bharali, 1989; Lynn and Cotsell, 1992) It has been suggested that the intensity of the vascular reaction reflects the degree of the nociceptor discharge and correlates with the magnitude of the perceived pain (Magerl et al., 1987).

Knowledge of the ability of nociceptors to signal mechanical pain stimuli has implications that go beyond the immediate understanding of pain mechanisms, because it provides an example that illustrates the relative importance of peripheral or central nervous components of the somatosensory processing for the conscious perception. It is often tacitly assumed that the mechanisms encoding acute pain lasting few minutes are simply the prolongation of the events activated by brief phasic stimuli that last seconds. We have explicitly tested this proposition by comparing the psychophysical magnitude estimates of pain and the neurogenic vasodilatation in alert humans with simultaneous microneurographic recordings of single nociceptive primary afferents during single and repetitive mechanical stimulation.

\section{Materials and Methods}

Subjects. A total of 39 healthy subjects ( 16 females and 23 males) aged 24-52 years participated in 55 experiments. In psychophysical experiments each individual entered a series of experiments only once. The investigations had been approved by the ethics committee of the medical faculty, and participants were instructed that the general purpose of the investigation was to study pain, but they were not informed about the specific aims. After having given informed consent the subjects were comfortably seated in a reclining chair and the left hand was positioned in a vacuum cast in an intermediate position between pro- and supination.

Mechanical stimulation. Mechanical stimuli were applied to the hairy skin on the dorsum of the hand in the innervation territory of the superficial radial nerve using a novel stimulation technique that has been described in detail elsewhere (Kohllöffel et al., 1991). Briefly, a small metal cylinder ( $12 \mathrm{~mm}$ length, $6 \mathrm{~mm}$ diameter, weight of $300 \mathrm{mg}$ ) was accelerated by pressurized air in a barrel that was perpendicularly directed against the skin. After impact the cylinder bounced back from the skin and was then quickly retrieved by suction. By varying the driving pressure in the harrel it is possible to adjust the impact speed and hence the force of the cylinder impinging on the skin. Different impact velocities ranging from 6 to $18 \mathrm{~m} / \mathrm{sec}$ were used in the present investigation. Because of the small mass of the cylinder, mainly the superficial layers of the skin are stimulated by this method (Kohllöffel et al., 1991). Depending on the impact velocity of the bullet a short sensation of nonpainful touch or of pain is elicited. In previous studies we have determined that this technique provides a reliable and reproducible method for the application of a wide range of nonpainful and painful mechanical stimuli (Kohllöffel et al., 1991).

Stimulus protocols. Two stimulation protocols were used. In the first series of experiments stimulus-response functions were obtained for single impact stimuli. All stimuli were delivered to the dorsum of the hand using an interstimulus interval of $60 \mathrm{sec}$. In psychophysical experiments the different stimulus intensities were presented in random order. In microneurographic experiments the stimuli were given in ascending order of intensity. This procedure was used as a precaution to prevent dislodgement of the electrode and loss of the recording caused by small involuntary movements of the hand that occurred in some subjects after application of stronger stimuli. As judged by the linear correlation coefficients of the psychophysical stimulus-response functions obtained in both experimental designs, there was no significant difference between the ascending (range of individual coefficients, 0.92 1.0 ; mean, 0.93 ) or random (range of individual coefficients, $0.90-1.0$; mean, 0.92) stimulus presentation. The coefficients obtained in the present investigation are also very similar to those of two independent sets of experiments that have previously found mean coefficients of 0.92 and 0.94 (Kohllöffel et al., 1991).

In the second series of experiments the effect of repetitive stimulation was investigated. Trains of five impact stimuli with a constant impact force of $14 \mathrm{~m} / \mathrm{sec}$ were applied at four different interstimulus intervals of $0.5,2,8$, and $32 \mathrm{sec}$ using an intertrain interval of $3 \mathrm{~min}$. This stimulus intensity was chosen because most subjects rated single impact stimuli of this intensity as painful. Trains with the four different interstimulus intervals were presented in random order in all experiments.

Psychophysical measurements. Subjects were asked to rate numerically the intensity of their sensations evoked by mechanical impact stimuli using magnitude estimation techniques (Stevens, 1975; Gracely, 1989). They were instructed to rate the intensity of the sensation which was associated with a just painful stimulus as 100 . Subjects were told to rate the perceived intensity of the sensation to other stimuli in proportion to this modulus whereby 200 would indicate an intensity of sensation that was twice as intense as the intensity of a just painful sensation. They were also asked to estimate the intensity of nonpainful or "prepain" sensations by giving proportionate values below 100 (Handwerker and Kobal, 1993). Stimulus intensities in this study were chosen to cover the nonpainful and painful range. Thus, the rating scale used in this study has the advantage of incorporating also prepain sensations in contrast to a visual analog scale for pain that uses "just noticeable pain sensation" and "the worst imaginable pain intensity" as anchors. Since nociceptors readily discharged at the lowest stimulus intensities (see Results) a large number of data points would have been lost, if only a scale for painful sensations were employed. Moreover, it would have also been impractical to use two separate scales for painful and nonpainful sensations. First, subjects described the sensations as a continuum rather than two strictly separate modalities. Second, the use of two scales would presuppose that the intensity of nonpainful sensations and painful mechanical impact stimuli are signaled by entirely different sets of primary afferents, which may not necessarily be the case.

Normalized stimulus-response functions were obtained by expressing each individual rating from one experiment as the percentage of the mean of all ratings of this session. We have previously determined that monotonic stimulus-response functions can be obtained with this method (Kohllöffel et al., 1991). Thus, for computation of the mcan normalized ratings, painful and nonpainful stimuli were used. As reported previously (Kohllöffel et al., 1991) this procedure reduces the interindividual variability without changing the characteristics of the stimulusresponse function (Fig. 1).

For trains of five stimuli the subjects were asked to estimate the overall magnitude of the sensations for the entire stimulus sequence, as estimations of each stimulus in the train was not possible for interstimulus intervals of $2 \mathrm{sec}$ or shorter. These stimuli were always rated as painful and therefore the mean normalized ratings are derived only from pain ratings.

Laser Doppler measurements of cutaneous blood flow. Cutaneous blood flow was assessed with a laser Doppler device (Perimed PFII) at a distance of $5 \mathrm{~mm}$ from the edge of the stimulated skin area. As cutaneous 
A

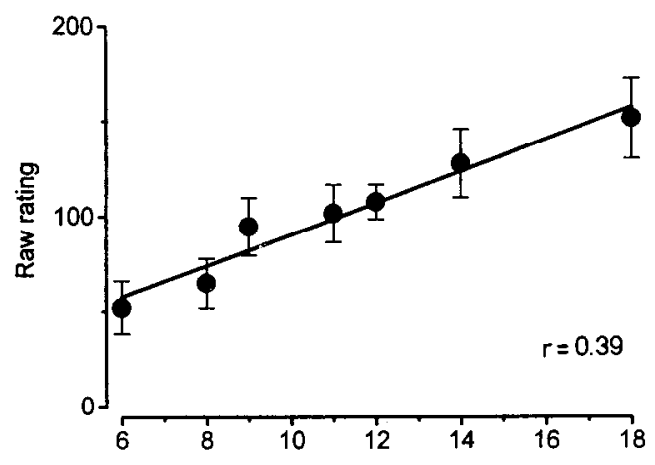

B

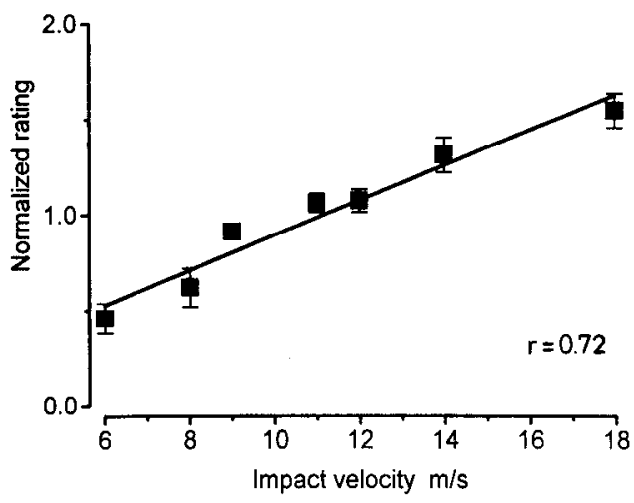

Figure 1. Stimulus-response function of the raw $(A)$ and normalized $(B)$ ratings obtained in this study following random presentation of the stimulus. Normalization does not affect the slope of the curve, but it increase the correlation coefficient, because of the reduction of interindividual variability.

blood flow often did not return to the prestimulus baseline close to a stimulus site, the probe and the stimulator were moved in psychophysical experiments to another skin area before application of the next stimulus. The laser Doppler device used in the present investigation does not provide absolute readings of blood flow, but measures the relative changes within a hemisphere of $1 \mathrm{~mm}$. The voltage output of the apparatus is proportional to the quantity and velocity of the red blood cells under the probe whereby the absence of flow corresponds to $0 \mathrm{~V}$. The baseline blood flow level obtained in the minute prior to each stimulation was subtracted, which could seemingly result in flow values below 0 . For quantitative comparison of blood flow changes, the area under the curve was computed (Magerl et al., 1987) for 3 min after a single impact stimulus or $10 \mathrm{~min}$ after the onset of stimulus trains. For the sake of clarity a running average over the adjacent data points was used to smooth the curves shown in the illustrations.

Microneurography. Microneurography (Hagbarth and Vallbo, 1967) was performed in 35 experiments on 31 participants using the superficial radial nerve at wrist level. Teflon-coated steel needles $(300 \mu \mathrm{m}$ shaft diameter, $10-20 \mu \mathrm{m}$ uninsulated tip diameter, $1-2 \mu \mathrm{m}$ resistance at 1 $\mathrm{kHz}$ ) (Handwerker et al., 1991) were percutaneously inserted into the nerve with an indifferent electrode placed subcutaneously nearby. During the search procedure for the nerve cathodal electrical pulses $(4 \mathrm{~V}$ intensity, $0.5 \mathrm{msec}$ stimulus duration, $2 \mathrm{~Hz}$ frequency) were delivered through the electrode until the subject reported strong paresthesia projecting to the nerve's innervation territory. With this electrode configuration threshold voltages below $1 \mathrm{~V}$ were usually indicative that the uninsulated tip of the electrode had penetrated into a fascicle of the nerve and this could be verified by recording multiunit activity evoked from mechanosensitive afferents by gently brushing the skin. Subsequently, minute adjustments of the needle were performed until singleunit activity could be clearly recorded. Neural activity was continuously displayed on an oscilloscope and fed into an AT-type computer equipped with a commercial I/O-card (DAP 1200/4; Microstar Laboratories, Bellevue, WA) for further quantitative analysis using a software package that had been specifically developed for microneurography (Forster and Handwerker, 1990). This software uses a cluster analysis as a templatematching paradigm to analyses spike recordings according to the form of the action potential rather than merely to its amplitude as in conventional window discriminators.

Characterization of primary afferent units. The search procedure for single units consisted of gently stroking or pinching the skin with forceps. Once a unit had been isolated its mechanical threshold was determined with calibrated von Frey hairs. Low-threshold afferents were further classified into slowly and rapidly adapting units according to established standard criteria (Vallbo et al., 1979; Johansson and Vallbo 1984). Nociceptive units were also tested with a standard radiant heat stimulus. Skin temperature was linearly increased by $1{ }^{\circ} \mathrm{C} / \mathrm{sec}$ from an adapting temperature of $32^{\circ} \mathrm{C}$ up to the tolerance level of the subject or maximally to $52^{\circ} \mathrm{C}$. The heat threshold was defined as the temperature level at which the instantaneous frequency of the discharge reached 1 impulse/ sec.

After having ascertained the receptive properties of a unit its conduction velocity was determined with transcutaneous electrical stimuli applied to the receptive field using cathodal constant voltage pulses (intensity up to $130 \mathrm{~V}, 0.5 \mathrm{msec}$ duration, $0.25 \mathrm{~Hz}$ frequency) that were applied through a hand-held metal electrode $(0.5 \mathrm{~mm}$ tip diameter) gently pressed against the skin with the reference electrode positioned at the ulnar side of the hand.

Data evaluation and statistics. The total number of impulses evoked by mechanical impacts was measured for $10 \mathrm{sec}$ following a single stimulus or for $180 \mathrm{sec}$ when trains of five impact stimuli were used. For single impact stimuli the instantaneous frequency of the response was also analyzed. The discharges of each unit were normalized by expressing each individual discharge as the proportion of the grand mean of the discharge obtained for one protocol (either single or repetitive stimuli as appropriate).

All values are given as the mean \pm standard error of the mean or as the median and the range between the 25 th and 75 th quartile. For statistical evaluation the data were analyzed using the STATisticA software package of StatSoft (Tulsa, OK). After having determined that the relevant data were normally distributed they were analyzed by univariate analysis of variance (ANOVA), by Student's paired $t$ test, or by linear regression.

\section{Results}

Psychophysical stimulus-response function and associated vasodilatation using single impact stimuli

In the first series of experiments on 10 subjects we studied the psychophysical stimulus-response functions and associated neurogenic blood flow changes produced by single impact stimuli applied to the dorsum of the hand. Depending on the impact velocity of bullet these stimuli evoked a brief sensation of nonpainful touch or of pain. The sensations had a superficial rather than deep quality, indicating that mainly skin and not the underlying tissue was stimulated. The median impact velocity at pain threshold was $11.0 \mathrm{~m} / \mathrm{sec}$ (quartile range, $3.3 \mathrm{~m} / \mathrm{sec}$ ) and magnitude estimation techniques showed a monotonically increasing stimulus-response function $\left(F_{6.63}-28.4 ; p<0.001\right.$, ANOVA). There was a close linear correlation $(r=0.92 ; p<$ $0.001)$ between the impact velocity of the stimulus and the normalized rating of the perceived sensation. For individual subjects the linear correlation coefficients of the stimulus-response functions varied from 0.90 to 1.00 .

The mechanical impact stimuli also resulted in increases of cutaneous blood flow measured outside the stimulated area. In 6 of 10 experiments vasodilatation was produced by mechanical stimuli that were not rated painful and this is also reflected in the grand mean of the blood flow responses (Fig. 2). While the mean pain threshold was $11.0 \mathrm{~m} / \mathrm{sec}$, a significant vasodilatation response lasting $3 \mathrm{~min}$ was already evoked by an impact stimulus of $9 \mathrm{~m} / \mathrm{sec}$. Above pain threshold the vasodilatation responses increased both in magnitude and duration and lasted longer than $3 \mathrm{~min}$. In the suprathreshold range there was a monotonic rise 

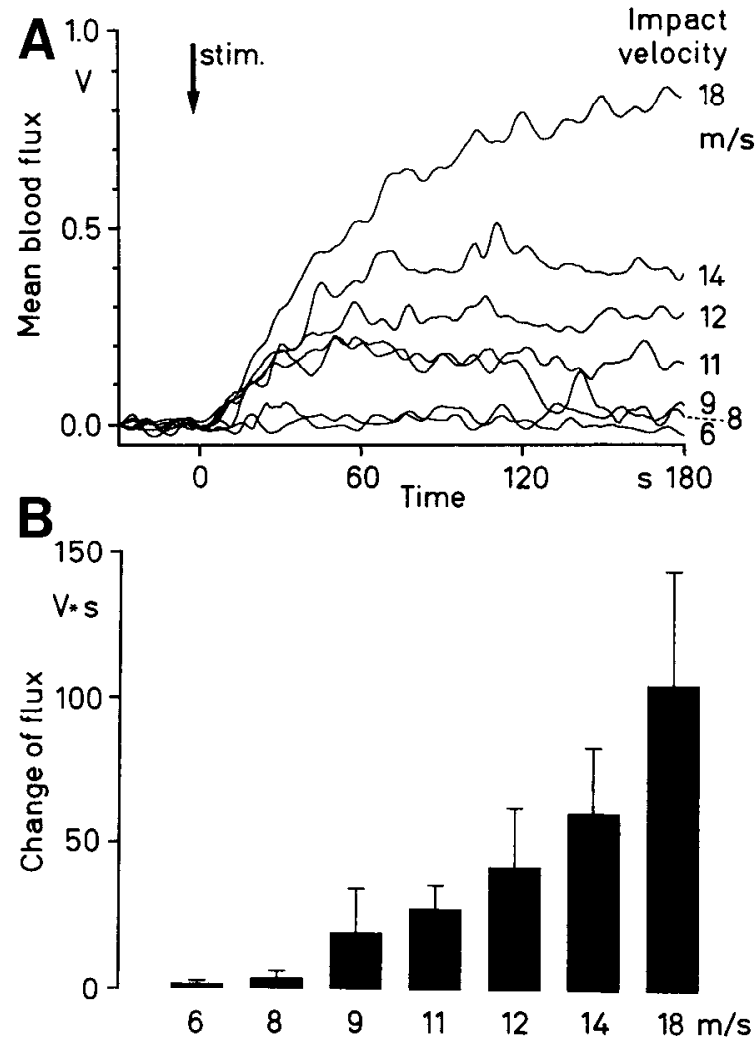

Figure 2. Graded cutaneous vasodilatation evoked by single impact stimuli. $A$, Grand mean of the laser Doppler measurements derived from 10 subjects. $B$, Quantification of the responses expressed as the integral of blood flow change over time. Impact velocities of $9 \mathrm{~m} / \mathrm{sec}$ or faster result in responses that are significantly different from baseline $(<0.05$, paired $t$ test).

of the vasodilatation with increasing stimulus intensity $\left(F_{6,63}=\right.$ $3.8 ; p<0.01$, ANOVA). Furthermore, there was a close linear correlation between the normalized increase of blood flow and the magnitude estimates of the evoked sensations $(r=0.64 ; p$ $<0.001)$.

\section{Microneurographic recordings of primary afferent neurons excited by mechanical impact stimuli}

A total of 23 single primary afferent units were recorded from the superficial radial nerve. Most units had their receptive fields on the dorsum of the hand and only few on the fingers (Fig. 3). Thus, the majority of the units innervated the same skin area that was also used for the blood flow measurements. Twelve of them were mechanosensitive primary afferents and on the hasis of their receptive properties they were classified as rapidly adapting $(n=4)$, or slowly adapting type I $(n=5)$ or type II $(n=3)$ units. The remaining 11 units had high mechanical thresholds and were $\mathrm{A} \delta$-fibers $(n=2)$ or C-fibers $(n=9)$.

\section{Unmyelinated nociceptive afferents}

The unmyelinated fibers had a conduction velocity of $0.78 \pm$ $0.03 \mathrm{~m} / \mathrm{sec}(n=9)$. Before the application of mechanical impact stimuli the fibers exhibited no ongoing activity and had a median von Frey hair threshold of $64 \mathrm{mN}$ (quartile range, $52 \mathrm{mN}$ ). Seven units responded also to radiant heat stimuli with a mean threshold of $43.4 \pm 0.9^{\circ} \mathrm{C}$.

All unmyelinated afferents were excited by mechanical impact
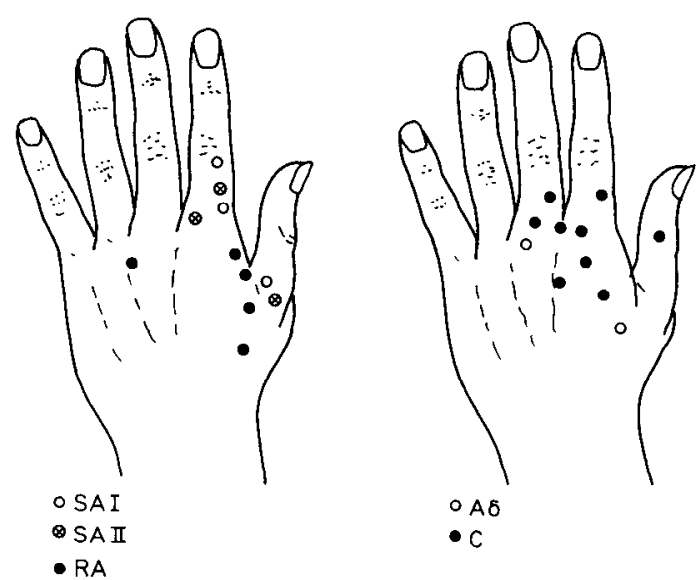

Figure 3. Distribution of the receptive fields of the units studied.

stimuli and six units responded readily to the lowest stimulus intensity used (Fig. 4). The mean discharge of the nine units evoked by an impact velocity of $6 \mathrm{~m} / \mathrm{sec}$ was $2.0 \pm 0.4$ impulses. Some particularly responsive units displayed maximal instantaneous discharge frequencies of more than $10 \mathrm{~Hz}$ at this stimulus intensity. Despite such activation of nociceptive primary afferents none of the subjects called this stimulus intensity painful. The impact velocity that was rated on average as painful $(11 \mathrm{~m} / \mathrm{sec})$ evoked $8.7 \pm 1.2$ action potentials and $16.7 \pm 2.6$ spikes were elicited by the highest impact velocity used in this study (Fig. $5 A$ ). Beyond threshold the units displayed a monotonically increasing stimulus-response function $\left(F_{6,52}=16.5 ; p\right.$ $<0.001$, ANOVA) and there was a highly significant correlation between the impact velocity and the number of evoked impulses $(r=0.69 ; p<0.001)$. Despite the discrepancy between the threshold for nociceptive unmyelinated afferents and the psychophysical pain threshold, there was a good linear correlation $(r=0.78 ; p<0.001)$ between the normalized discharge of the
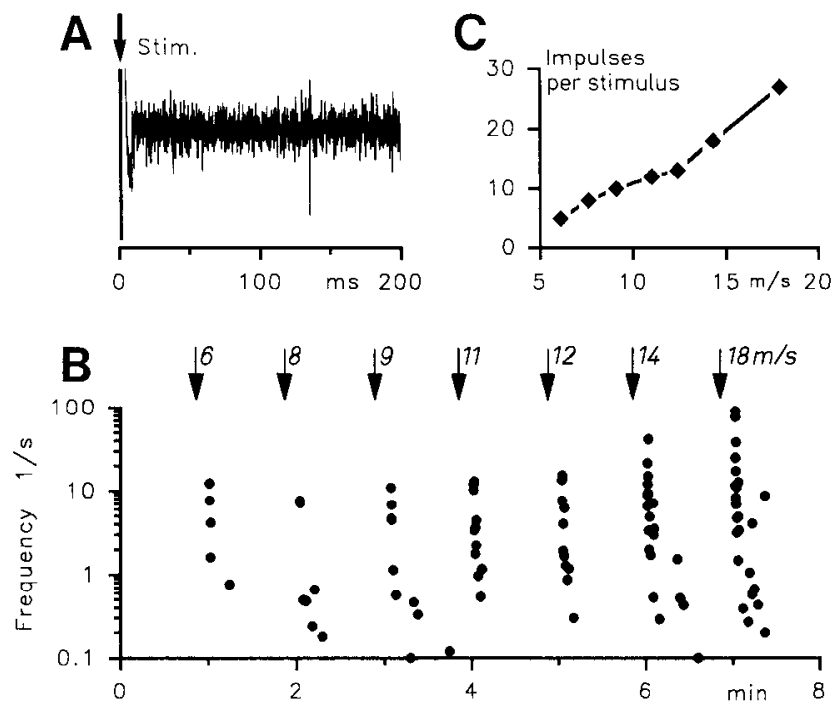

Figure 4. Specimen of an unmyelinated nociceptive afferent unit responding to impact stimuli. $A$, Electrical identification of the unit (several sweeps are superimposed) using transcutaneous electrical stimulation (Stim.). B, Instantaneous frequency histogram of the response to impact stimuli delivered with increasing intensity (impact velocity from 6-18 m/sec). $C$, Stimulus-response function of the unit. 

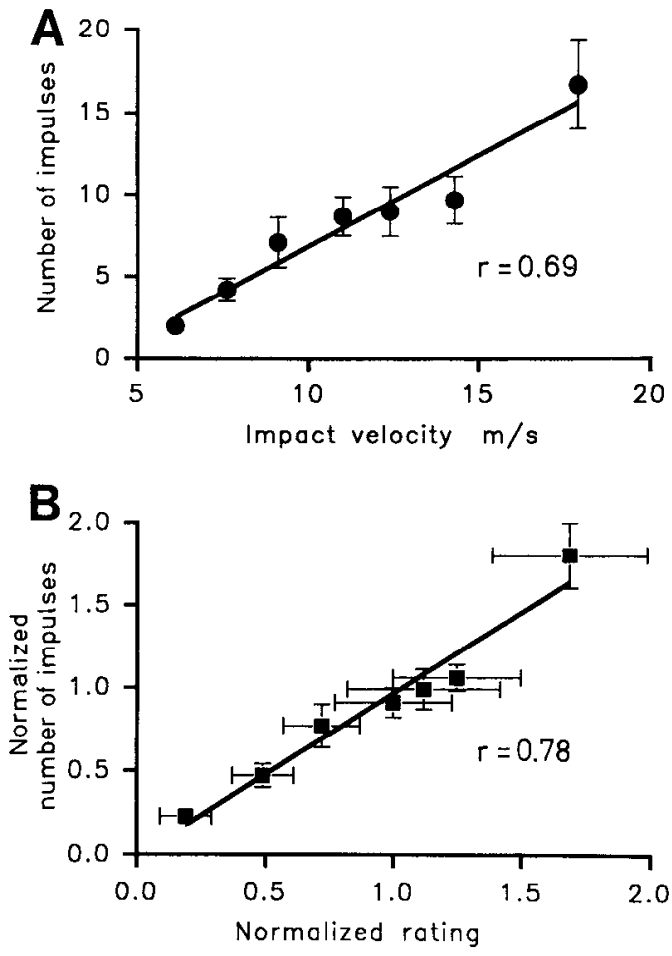

Figure 5. A, Mean stimulus-response function of nine unmyelinated nociceptive afferents tested with impact stimuli. $B$, Correlation between the normalized number of action potentials of the units and the normalized magnitude estimations of sensation obtained simultaneously from the subjects.

units (derived from the number of spikes evoked by a stimulus) and the simultaneously obtained normalized psychophysical magnitude estimates (Fig. $5 B$ ).

By contrast there was no significant correlation between the mean instantaneous discharge frequency of the neural responses (derived from the interspike intervals) and the stimulus intensity or the estimations of the sensory magnitude. The mean instantaneous discharge frequency of the evoked response did neither encode the stimulus intensity ( $r=0.22$; Fig. $6 A$ ), nor was there a significant correlation between the normalized rating and the normalized discharge frequency $(r=0.19$; Fig. $6 B$ ).

These results were also confirmed when correlations were computed for individual units. The correlation coefficients between the impact velocity and the number of action potentials varied from 0.22 to 0.98 while the respective correlation coefficient varied from 0.05 to 0.45 for the mean instantaneous discharge frequency. The correlation coefficient between the psychophysical ratings and the number of action potentials ranged from 0.51 to 0.97 , but only from 0.01 to 0.80 for the mean instantaneous discharge frequency. In a direct comparison the highest coefficient was obtained in eight of the nine fibers for the correlation of the ratings with the total number of action potentials rather than with the mean instantancous discharge frequency. This indicates that the instantaneous frequencies of neural discharge of C-fibers are probably not a crucial parameter for the sensory discriminative aspect of short-lasting mechanical pain stimuli.

\section{Thin myelinated nociceptive afferents}

The two thin myelinated units exhibited qualitatively similar responses as the unmyelinated units, except that the total num-
A
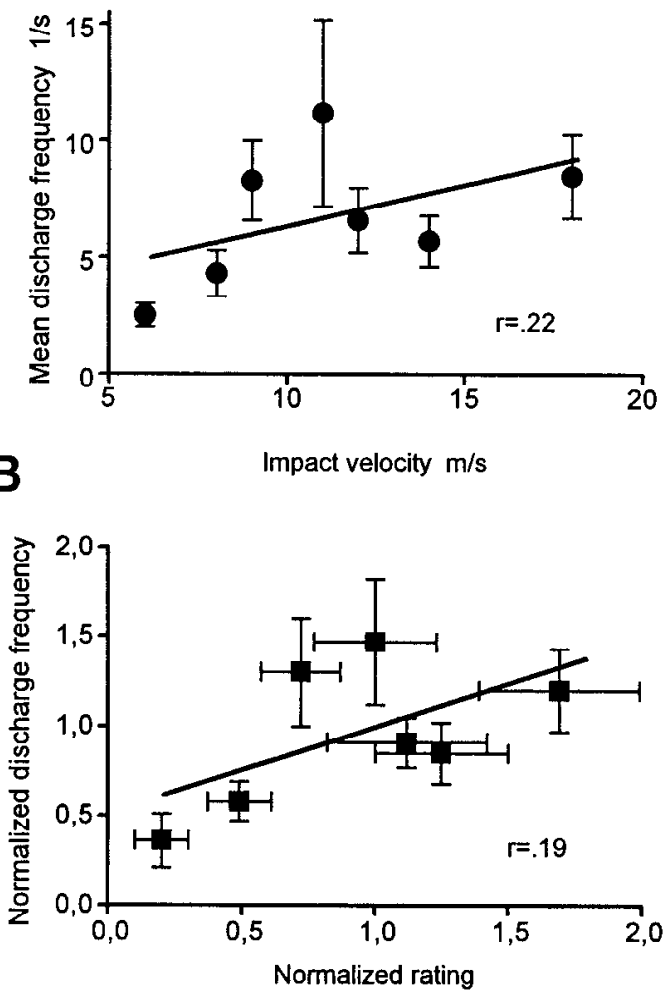

Figure 6. A, Mean discharge frequencies of nine unmyelinated nociceptive afferents tested with impact stimuli. $B$, Correlation between the normalized discharge frequency of the units and the normalized magnitude estimations of sensation obtained simultaneously from the subjects.

ber of action potentials elicited by any stimulus was considerably higher (Fig. 7). Both units responded to the lowest impact velocities that were not rated as painful.

\section{Low-threshold mechanosensitive afferents}

All low-threshold mechanoreceptive afferents were excited by the impact stimuli. Rapidly adapting afferents discharged one to three impulses for every stimulus regardless of its impact velocity. Type I slowly adapting afferents responded more vigorously to the stimuli, but their discharge patterns differed from those of the nociceptive units. Some myelinated fibers discharged progressively less when the stimulus intensity increased and thus displayed inverse stimulus-response functions (Fig. 8). The lowest stimulus intensity $(6 \mathrm{~m} / \mathrm{sec})$ yielded a mean discharge of $12.8 \pm 3.5$ impulses $(n=5)$ and the discharge at stronger stimulus intensities varied from 21.0 to 26.4 (range of SEM, 4.6-10.0), so no significant stimulus-response function was obtained for this receptor type $\left(F_{6.49}=0.9 ; p>0.4\right.$, ANOVA). There was thereforc also no significant correlation $(r=-0.19$; $p>0.5$ ) between the normalized rating and the normalized number of action potentials. This means that mechanosensitive type I slowly adapting fibers cannot signal the stimulus intensity of mechanical impact stimuli used in the present investigation. Strong impact stimuli often led also to a transient desensitization of the receptors to mechanical stimuli (Fig. 9). This desensitization was more pronounced after high stimulus intensities or with repetitive stimulation and could last for $3 \mathrm{~min}$ after a single 

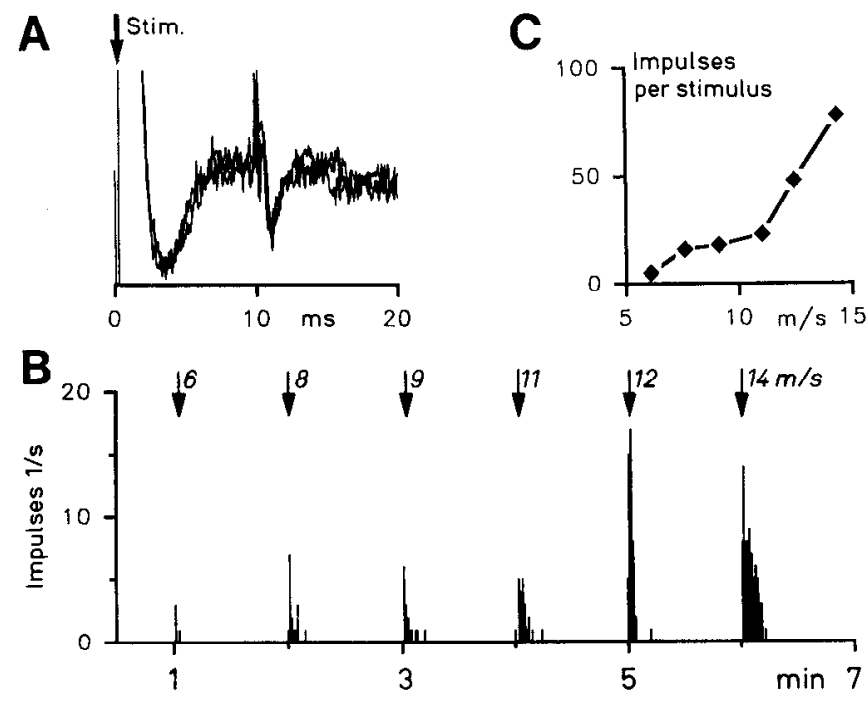

Figure 7. Spccimen of a thin myclinated nociceptive afferent unit responding to impact stimuli. $A$, Electrical identification of the unit (several sweeps are superimposed) using transcutaneous electrical stimulation (Stim.). B, Histogram (bin width, 1 sec) of the response to impact stimuli delivered with increasing intensity (impact velocity from 6-14 $\mathrm{m} / \mathrm{sec}$; higher velocities were not tested because of the subject's refusal). $C$, Stimulus-response function of the unit.

impact stimulus. Receptor sensitivity recovered spontaneously in all units tested.

The type II slowly adapting afferents displayed more complex discharge patterns (Fig. 10). These units discharged spontaneously prior to stimulus application and often displayed biphasic response with an initial increase that was followed by an inhibition. During the abolition or reduction of resting activity immediately after an impact stimulus, the units often also became desensitized to stimulation with von Frey filaments. Based on the nonmonotonic and reverse slope of the stimulus-response functions, it is unlikely that the large myelinated mechanosensitive afferents contribute significantly to the encoding of mechanical impact stimuli.

\section{Psychophysical stimulus-response function and associated vasodilatation upon trains of impact stimuli}

In a second series of experiments we tested the effect of different interstimulus intervals of five impact stimuli delivered with a constant velocity of $14 \mathrm{~m} / \mathrm{sec}$. In 10 experiments we investigated the psychophysical stimulus-response functions and the associated neurogenic blood flow response at different interstimulus intervals. Magnitude estimates of pain intensity were conspicuously frequency dependent and higher pain ratings were obtained with shorter interstimulus intervals $\left(F_{3,36}=5.1 ; p<0.01\right.$, ANOVA).

In contrast, simultaneous blood flow measurement showed that the magnitude of vasodilatation decreased significantly $\left(F_{3,36}\right.$ $=3.1 ; p<0.05$, ANOVA) from lower to higher intratrain frequencies while the mean magnitude of the rating increased (Fig. 11). This is opposite to the results obtained with single impact stimuli were a close positive correlation between sensory magnitude estimates and neurogenic vasodilatation had been found.

Stimulus-response functions of nociceptive afferents tested with trains of impact stimuli

The effect of different interstimulus intervals was studied in seven unmyelinated nociceptive units, and a representative ex-

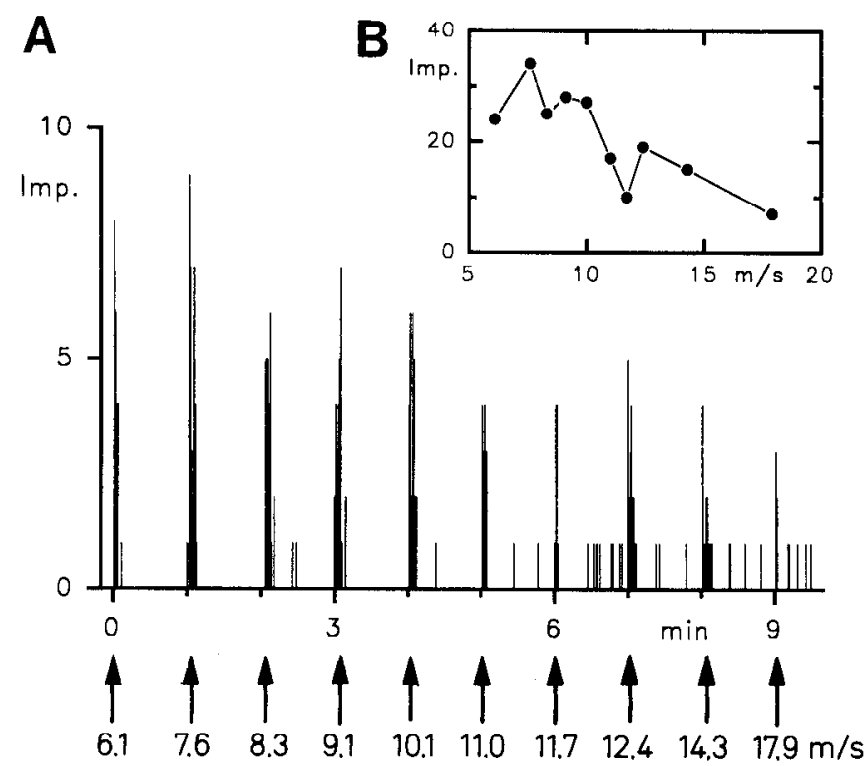

Figure 8. A, Histogram of a type I slowly adapting mechanosensitive afferent unit responding to impact stimuli $(6.1-17.9 \mathrm{~m} / \mathrm{sec}) . B$, Stimulus-response function.

ample is illustrated in Figure 12. The mean number of action potentials increased from $15.9 \pm 10.1$ at an interstimulus interval of $0.5 \mathrm{sec}$ to $33.7 \pm 12.0$. at an interstimulus interval of $32 \sec \left(F_{3.24}=3.2 ; p<0.05\right.$, ANOVA $)$. Although longer interstimulus intervals evoked larger numbers of action potentials, they were dispersed over a much longer time and therefore the stimulus-response functions based on the cumulative discharge became flatter. When the total number of action potentials recorded from the unmyelinated afferents was plotted against the
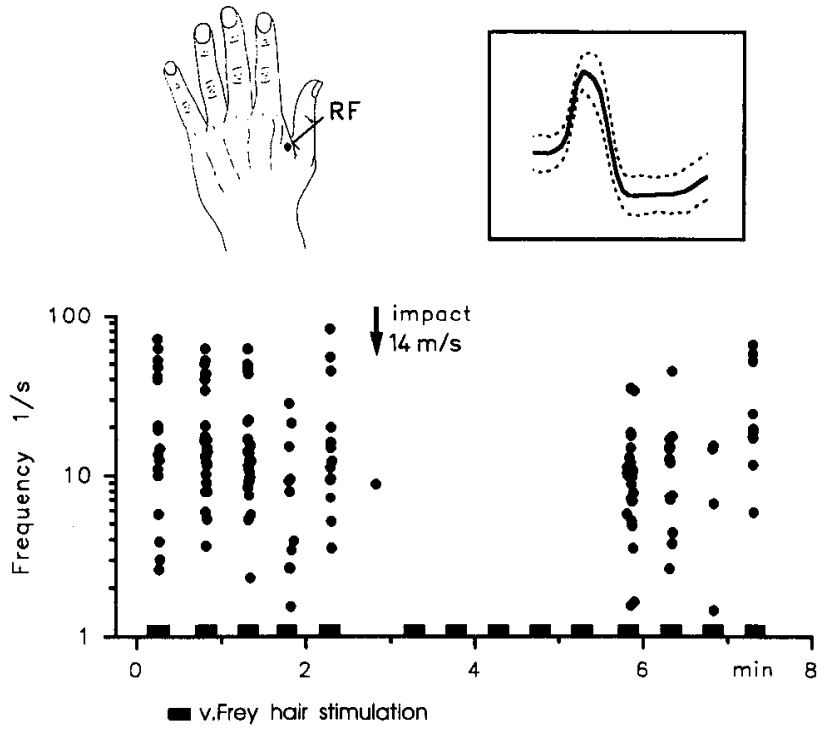

Figure 9. Type I slowly adapting mechanosensitive afferent unit that was desensitized by a single painful impact stimulus (impact velocity, $14 \mathrm{~m} / \mathrm{sec}$ ). The unit responded reliable every $30 \mathrm{sec}$ to a von Frey hair exerting a bending force of $64 \mathrm{mN}$. Following the impact stimulus the unit was desensitized for more than minutes until the response to von Frey hair stimulation recovered. Inset shows the location of the receptive field and the shape of the action potential. Dotted lines indicate the borders of the template used by the software for identification of spikes. 


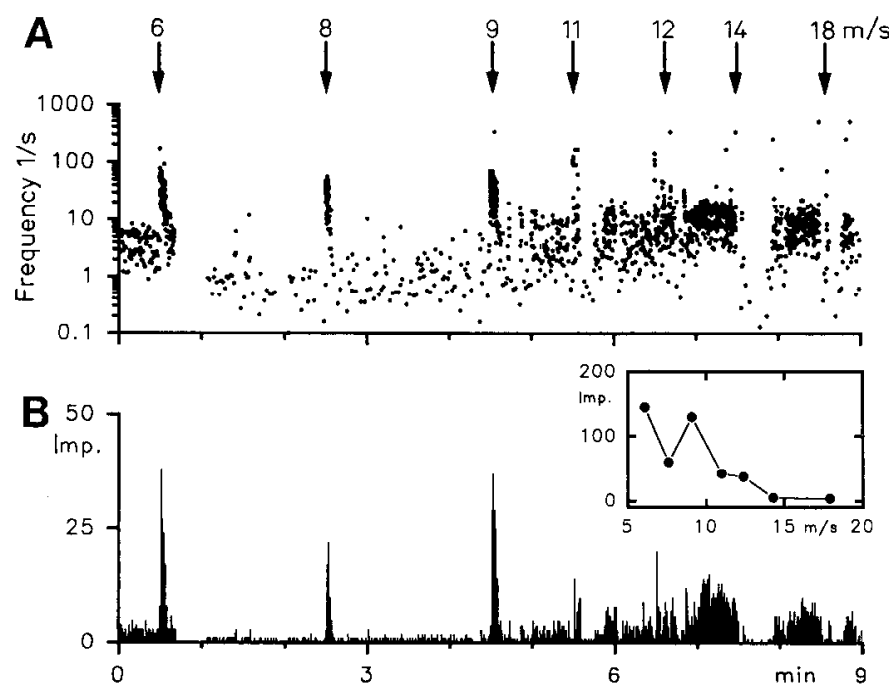

Figure 10. Type II slowly adapting mechanosensitive afferent unit responding to impact stimuli $(6-18 \mathrm{~m} / \mathrm{sec}) . A$, Instantaneous frequency histogram of the response. $B$, Histogram of the response. Inset shows the stimulus-response function of the unit.

simultaneously obtained magnitude estimates of the pain (Fig. 13) there was a significant negative correlation $(r=-0.41 ; p<$ 0.05 ). The two thin myelinated units had qualitatively similar discharge properties. We did not attempt to study large myelinated fibers with repetitive stimulation because of their frequent desensitization.

\section{Sensitization of unmyelinated afferents following mechanical impact stimuli}

Following the application of the impact stimuli the radiant heat and von Frey hair thresholds were retested. While there was no change in the median von Frey hair threshold, we observed an increased responsiveness to the standard heat stimulus. There was a small but significant drop of the heat threshold of $2.0^{\circ} \mathrm{C}$ from $43.4 \pm 0.9^{\circ} \mathrm{C}$ to $41.4 \pm 1.1^{\circ} \mathrm{C}(p<0.05$, paired $t$ test $)$, indicating sensitization. The increased responsiveness of unmyelinated units to heat stimuli corresponded to the increased painfulness of the heat stimulus reported by most subjects after the mechanical stimulation.

\section{Discussion}

The principle finding of the present investigation is that human nociceptive primary afferents have a differential ability to encode mechanical pain for single and repetitive mechanical stimuli. Pain of single stimuli is signaled by the total number of action potentials while the magnitude of pain evoked by repetitive stimuli depends critically on the temporal pattern of the discharge. The experiments also showed that thin myelinated and unmyelinated nociceptive afferents probably encode the magnitude of scnsation produccd by single impact stimuli by the absolute number of action potentials rather than by the instantaneous frequency of the discharge. These results are in agreement with previous investigations that showed the nociceptor discharge accounts for the magnitude of brief heat pain stimuli (Gybels et al., 1979; Meyer and Campbell, 1981; LaMotte et al., 1982; Adriaensen et al., 1983). In normal hairy skin there is a linear correlation between the mean nociceptor discharge and the corresponding pain rating (LaMotte et al., 1983; To-
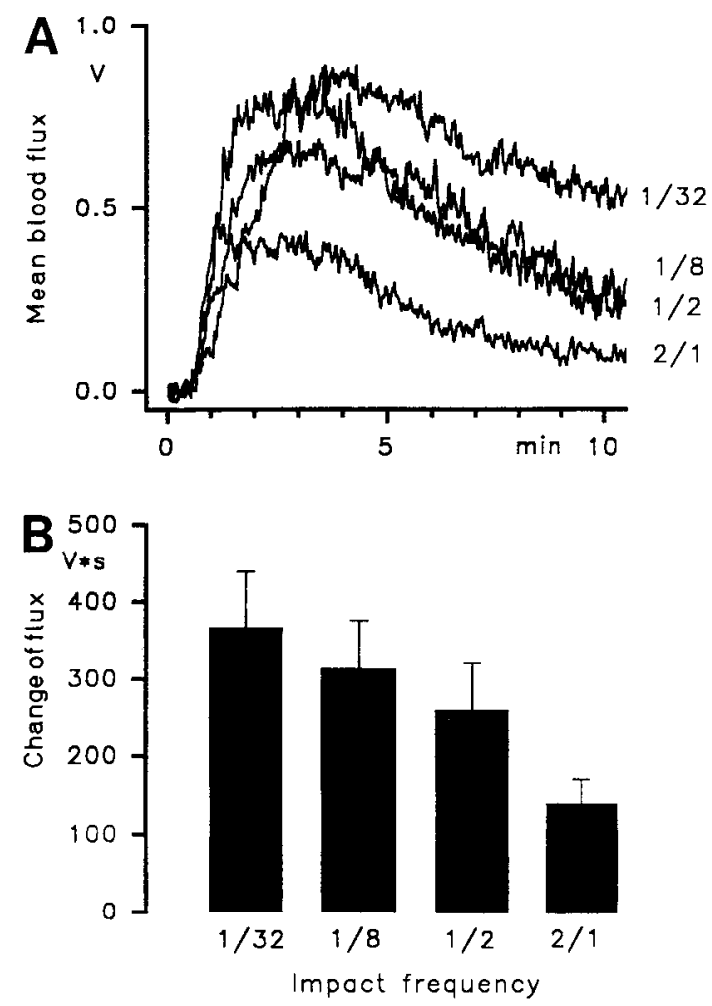

Figure 11. Cutaneous vasodilatation following a train of five impact stimuli at constant stimulus intensity (impact velocity, $14 \mathrm{~m} / \mathrm{sec}$ ) given at different intrastimulus frequencies. $A$, Grand mean of the laser Doppler measurements derived from 10 subjects. The first stimulus of each train was given at $0 \mathrm{~min} . B$, Quantification of the responses expressed as the integral of blood flow change over time.

rebjörk et al., 1984). Moreover, fatigue of this receptor population usually results in reduced heat pain sensations (LaMotte et al., 1983; Adriaensen et al., 1984b; Torebjörk et al., 1984). By contrast, nociceptors of primates can become sensitized following (Meyer and Campbell, 1981; Campbell and Meyer, 1983; Torebjörk et al., 1984) injurious skin stimuli and it is generally agreed that the temporal and spatial pattern of this sensitization correlates well with the corresponding psychophysical changes of an increased pain perception (Treede et al., 1992; Handwerker and Kobal, 1993). However, it is also evident that sensitization of afferents alone does not fully explain the psychophysical changes, and central spatial or temporal summation probably contributes to the changes of the observed pain perception (LaMotte et al., 1983; Torebjörk et al., 1984; Treede et al., 1992; Handwerker and Kobal, 1993). Thus, several independent lines of evidence converge to the conclusion that the pains evoked by brief mechanical and thermal stimuli are signaled by the number of action potentials of nociceptive afferents. A linear correlation between the magnitude of pain and the total number of impulses has also been demonstrated with transcutaneous (Magerl et al., 1987) or intraneural microstimulation (Lundberg et al., 1992) of cutaneous nociceptors although the pattern of the discharge can influence the magnitude estimates of pain also (see below). This could mean that the afferent information generated by brief noxious stimuli in normal skin will be subjected to relatively little modification by central nervous processing. It alsu suggests that the frequency modulation of the nociceptor discharge is not a major factor in the coding of stimulus intensity 

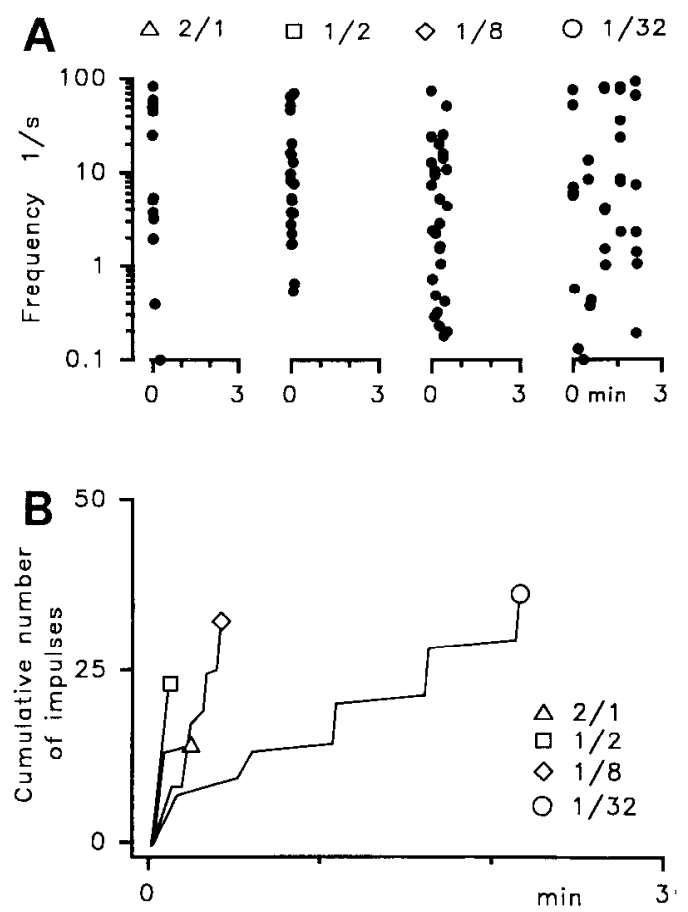

Figure 12. A, Instantaneous frequency histogram of an unmyelinated unit to trains of five impact stimuli (constant impact velocity of $14 \mathrm{~m} /$ $\mathrm{sec}$ ) delivered at different interstimulus frequencies. $B$, Cumulative number of impulses evoked by each stimulus train.

and the corresponding magnitude of sensation following very short mechanical stimuli.

Despite the good correlation between the nociceptor discharge and the magnitude estimates of the sensation, it was equally plain that the lowest stimulus intensities that were not rated painful evoked neurogenic vasodilatation and a C-fiber discharge. Nonpainful stimuli could elicit instantaneous discharge with interspike intervals of less than $100 \mathrm{msec}$, that is, instantaneous frequencies of more than $10 \mathrm{~Hz}$. This indicates that a brief high-frequency burst of unmyelinated nociceptors is not necessarily sufficient to induce pain. On the other hand, the mean number of action potentials evoked by a painful impact stimulus was around 8 impulses. The discrepancy between nociceptor discharge and pain perception has also been observed for other mechanical (von Frey hairs) (Van Hees and Gybels, 1981; Adriaensen et al., 1984a), thermal (Gybels et al., 1979; Van Hees and Gybels, 1981), and chemical ( $\Lambda$ driaensen et al., 1980) stimuli. These studies have estimated that mean nociceptor discharge rates exceeding $0.5-1.0 \mathrm{~Hz}$ during a maintained stimulus are required to evoke painful sensations. This could mean that temporal summation of a certain number of impulses in nociceptive afferents is necessary for the conscious perception of pain in humans, in spite of the limited correlation of the frequency modulation of the discharge with the perceived sensation.

The monotonic increase of the total nociceptor discharge following impact stimulation of increasing stimulus intensity is also reflected by the corresponding increase of vasodilatation. This indicates that the total number of action potentials is also the determinant for the magnitude of the neurogenic vasodilatation after a single noxious stimulus. Such parallel changes of pain sensation and vasodilatation have also been observed after
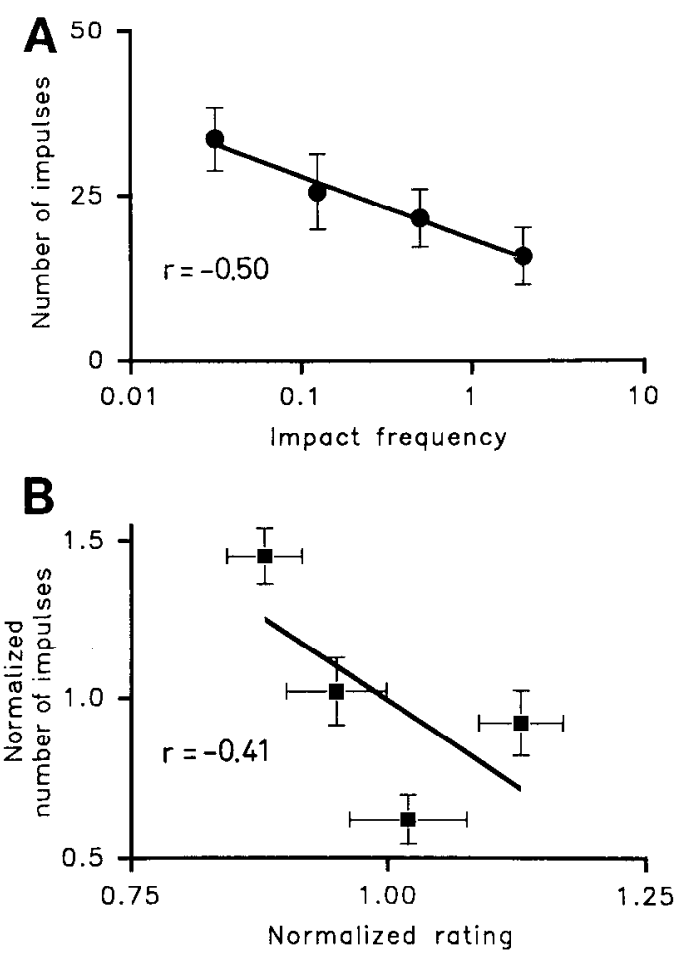

Figure 13. A, Mean stimulus-response function of seven unmyelinated nociceptive afferents tested with a train of five impact stimuli (constant impact velocity of $14 \mathrm{~m} / \mathrm{sec}$ ). $B$, Correlation between the normalized discharge of the units and the normalized magnitude estimations of stimulus intensity obtained simultaneously from the subjects.

thermal (Lynn and Cotsell, 1991), electrical (Magerl et al., 1987; Szolcsányi, 1988), and chemical stimuli (Magerl et al., 1990).

A clear discrepancy between nociceptor activity and magnitude of pain became obvious when trains of impact stimuli were used. Although the total number of impulses decreased with shorter interstimulus intervals, the psychophysical magnitude estimates of the corresponding pain increased. Of course, the evoked nociceptor activity was then elicited in a shorter interval and therefore the slope of the cumulative number of spikes evoked from the nociceptors is actually steeper (Fig. 13). This provides evidence that summation of nociceptor activity is an important determinant of the magnitude of evoked pain when more than one brief stimulus is applied. The temporal dependence of the magnitude of $\mathrm{C}$-fiber evoked pain has also been shown in a series of experiments by Price and collcagues (Price et al., 1977, 1978; Price, 1988). They applied trains of short heat pulses to evoke first and second, delayed pain in humans and found that both pain components behaved differently. While there was a gradual decrease of the first component of pain there was a gradual buildup of the second pain component when interstimulus intervals became shorter than $3 \mathrm{sec}$. Using neurophysiological recordings in monkey, they went on to show that impulse rates in both thin myelinated and unmyelinated nociceptive afferents decreased their discharge with stimulus repetition and they concluded that this caused the decline of the magnitude estimates of the first pain component. However, recordings from spinothalamic tract neurons revealed a summation of the C-fiber evoked discharge, indicating substantial temporal summation of unmyelinated nociceptive neurons despite the fatigue of the primary afferent input occurring with stimulus 
repetition. They concluded that the slow temporal summation of afferent activity onto central neurons is therefore important for the magnitude of the perceived pain.

A similar conclusion has recently been obtained in humans using intraneural microstimulation. It has been determined that the magnitude of the pain evoked by electrical excitation of nociceptive afferents depends on the pattern of stimulation (Lundberg et al., 1992). A pattern that mimicked the natural discharge of nociceptors and consisted of a dynamic high-frequency discharge that settled on a lower frequency was generally perceived as more painful than the same number of impulses delivered over the same time with a regular interstimulus interval.

The summation of pain sensations observed in human experiments has many features in common with the slow excitability increase of higher-order neurons studied in animals. It has been found that repetitive electrical stimulation of $\mathrm{C}$-fibers results in the progressive excitability increase of spinal cord neurons (Wall and Woolf, 1984; Willis and Coggeshall, 1991; Dubner and Ruda, 1992; Woolf, 1992) although there are different mechanisms that could account for this phenomenon. NMDA receptor antagonists block the C-fiber evoked summation of activity following repetitive stimulation, but not the excitation of the spinal cord neurons by single impulses. This has been interpreted as a release of glutamate from central C-fiber terminals leading to a postsynaptic potentiation of the responses (Davies and Lodge, 1987; Dickenson and Sullivan, 1987; Thompson et al., 1990). Others have also found that the C-fiberevoked summation can be reduced by application of antagonists to neuropeptides, notably substance P (Kelstein et al., 1990). As application of substance $P$ can induce a sustained depolarization of spinal cord neurons (Urban and Randić, 1984) it has been concluded that neuropeptides could also have such modulatory role. More recently, it has been shown that tachykinins potentiate the response of dorsal horn neurons to application of NMDA receptor agonists (Dougherty and Willis, 1991; Rusin et al., 1992).

The results of the present study also bear on the understanding of mechanical hyperalgesia that can develop after tissue injury (Handwerker and Reeh, 1991; LaMotte, 1992; Treede et al., 1992). There is good evidence that at least some components of this hyperalgesia are transmitted by nociceptive afferents (Cervero et al., 1991; LaMotte et al., 1991; Koltzenburg et al., 1992). By contrast, most neurophysiological studies have failed to show convincingly threshold reduction of the nociceptors to mechanical stimuli under conditions that produce profound hyperalgesia (Handwerker and Reeh, 1991; LaMotte, 1992; Treede et al., 1992). The fact that the magnitude of mechanical pain critically depends on central processes even in normal tissues therefore invites speculations that an altered central processing of unchanged nociceptive afferent inputs could contribute to mechanical hyperalgesia.

With repetitive stimulation a clear discrepancy between the degree of vasodilatation and the corresponding pain sensation was observed. This indicates that nociceptive afferents possess different frequency optima for the effectiveness of their central and peripheral function. In rodents maximal vasodilatation can be produced with frequencies as low as $0.1 \mathrm{~Hz}$ (Szolcsányi, 1984, 1988; Lynn and Shakhanbeh, 1988) and this frequency may be too low to evoke pain or any other sensation. A discrepancy between the magnitude of sensations and the corresponding neurogenic inflammation has also been found when different nociceptive-specific stimuli have been compared (Simone et al., 1987, 1989; McMahon and Koltzenburg, 1992; Treede, 1992).

In conclusion, the present results have shown that unmyelinated nociceptive afferents exhibit different properties for their central afferent and their peripheral efferent function. For the pain processing we have shown that temporal summation is relatively unimportant when single brief stimuli are used. With stimulus repetition the magnitude of the perceived pain depends on the temporal summation at central synapses, although this summation is probably not achieved by a simple modulation of the interspike interval of individual C-fibers. An alternative explanation is that the magnitude of pain is encoded by the average discharge rates in populations of units and that slow excitability increases of central sensory neurons become increasingly more important determinants of the magnitude of pain.

\section{References}

Adriaensen H, Gybels J, Handwerker HO, Van Hees J (1980) Latencies of chemically cvoked discharges in human cutaneous nociceptors and of the concurrent subjective sensations. Neurosci Lett 20:55-59.

Adriaensen H, Gybels J, Handwerker HO, Van Hees J (1983) Response properties of thin myelinated (A-delta) fibers in human skin nerves. J Neurophysiol 49:111-122.

Adriaensen H, Gybels J, Handwerker HO, Van Hees J (1984a) Nociceptor discharges and sensations due to prolonged noxious mechanical stimulation - a paradox. Hum Neurobiol 3:53-58.

Adriaensen H, Gybels J, Handwerker HO, Van Hees J (1984b) Suppression of $\mathrm{C}$-fibre discharges upon repeated heat stimulation may explain characteristics of concomitant pain sensations. Brain Res 302 : 203-211.

Campbell JN, Meyer RA (1983) Sensitization of unmyelinated nociceptive afferents in monkey varies with skin type. J Neurophysiol 49:98-110.

Campbell JN, Raja SN, Cohen RH, Manning AAK, Meyer RA (1989) Peripheral neural mechanisms of nociception. In: Textbook of pain, Vol 2 (Wall PD, Melzack R, eds), pp 22-45. Edinburgh: Churchill Livingstone.

Cervero F, Meyer RA, Campbell JN (1991) Prickle and pain in normal and hyperalgesic skin: evidence that low threshold mechanoreceptors are responsible for the pain of secondary hyperalgesia. Soc Neurosci Abstr 17:293

Chahl LA (1988) Antidromic vasodilatation and neurogenic inflammation. Pharmacol Ther 37:275-300.

Davies SN, Lodge D (1987) Evidence for the involvement of $N$-methylaspartate receptors in "wind-up" of class 2 neurones in the dorsal horn of the rat. Brain Res 424:402-406.

Dickenson AH, Sullivan AF (1987) Evidence for a rolc of the NMDA receptor in the frequency dependent potentiation of deep rat dorsal horn nociceptive neurones following $\mathrm{C}$ fibre stimulation. Neuropharmacology 26:1235-1238.

Dougherty PM, Willis WD (1991) Enhancement of spinothalamic neuron responses to chemical and mechanical stimuli following combined micro-iontophoresis of $N$-methyl-D-aspartic acid and substance P. Pain 47:85-93

Dubner R, Ruda M (1992) Activity-dependent neuronal plasticity following tissue injury and inflammation. Trends Neurosci 15:96103.

Forster C, Handwerker HO (1990) Automatic classification and analysis of microneurographic spike data using a PC/AT. J Neurosci Methods 31:109-118.

Graccly RH (1989) Methods of testing pain mechanisms in normal man. In: Textbook of pain, Vol 2 (Wall PD, Melzack R, eds), pp 257268. Edinburgh: Churchill Livingstone.

Gybels J, Handwerker HO, Van Hees J (1979) A comparison between the discharges of human nociceptive nerve fibres and the subject's ratings of his sensations. J Physiol (Lond) 292:193-206.

Hagbarth KE, Vallbo AB (1967) Mechanoreceptor activity recorded percutaneously with semi-microelectrodes in human peripheral nerves. Acta Physiol Scand 69:121-122.

Handwerker HO, Kobal G (1993) Psychophysiology of experimentally induced pain. Physiol Rev 73:639-671. 
Handwerker HO, Reeh PW (1991) Pain and inflammation In: Proceedings of the VIth World Congress on Pain (Bond MR, Charlton JE, Woolf CJ, eds), pp 59-70. Amsterdam: Elsevier.

Handwerker HO, Iggo A, Zimmermann M (1975) Segmental and supraspinal actions on dorsal horn neurons responding to noxious and non-noxious skin stimuli. Pain 1:147-165.

Handwerker HO, Anton F, Reeh PW (1987) Discharge patterns of afferent cutaneous nerve fibers from the rat's tail during prolonged noxious mechanical stimulation. Exp Brain Res 65:493-504.

Handwerker HO, Forster C, Kirchoff C (1991) Discharge properties of human C-fibres induced by itching and burning stimuli. J Neurophysiol 66:307-315.

Johansson RS, Vallbo Åb (1984) Properties of cutaneous mechanoreceptors in the human hand related to touch sensation. Hum Neurobiol 3:3-14.

Kandel ER, Jessell TM (1991) Touch. In: Principles of neural science Vol 3 (Kandel ER, Schwartz JH, Jessell TM, eds), pp 367-384. Amsterdam: Elsevier.

Kelstein DE, Price DD, Hayes RL, Mayer DJ (1990) Evidence that substance P selectively modulates $C$-fiber evoked discharges of dorsal horn nociceptive neurons. Brain Res 526:291-298.

Kohllöffel LUE, Koltzenburg M, Handwerker HO (1991) A novel technique for the evaluation of mechanical pain and hyperalgesia Pain 46:81-87.

Koltzenburg M, Lundberg LER, Torebjörk HE (1992) Dynamic and static components of mechanical hyperalgesia in human hairy skin. Pain 51:207-219.

LaMotte RH (1992) Subpopulations of "nocifensor neurons" contributing to pain and allodynia, itch and allokinesis. APS J' 1:115126.

LaMotte RH, Thalhammer JG, Torebjörk HE, Robinson CJ (1982) Peripheral neural mechanisms of cutaneous hyperalgesia following mild injury by heat. J Neurosci 2:765-781.

LaMotte RH, Thalhammer JG, Robinson CJ (1983) Peripheral neural correlates of magnitude of cutaneous pain and hyperalgesia: a comparison of neural events in monkey with sensory judgments in human. J Neurophysiol 50:1-26.

LaMotte RH, Shain CN, Simone DA, Tsai EF (1991) Neurogenic hyperalgesia: psychophysical studies of underlying mechanisms. J Neurophysiol 66:190-211.

LaMotte RH, Lundberg LER, Torebjörk HE (1992) Pain, hyperalgesia and activity in nociceptive $C$ units in humans after intradermal injection of capsaicin. J Physiol (Lond) 448:749-764.

Lisney SJW, Bharali LAM (1989) The axon reflex: an outdated idea or a valid hypothesis. News Physiol Sci 4:45-48.

Lundberg LEK, Jørum E, Holm E, Torebjörk HE (1992) Intraneural electrical stimulation of cutaneous nociceptive fibres in humans: effects of different pulse patterns on magnitude of pain. Acta Physiol Scand 146:41-48.

Lynn B (1988) Neurogenic inflammation. Skin Pharmacol 1:217-224.

Lynn B, Cotsell B (1991) The delay in onset of vasodilatator flare in human skin at increasing distances from a localized noxious stimulus. Microvasc Res 41:197-202.

Lynn B, Cotsell B (1992) Blood flow increases in the skin of the anaesthetized rat that follow antidromic sensory nerve stimulation and strong mechanical stimulation. Neurosci Lett 137:249-252.

Lynn B, Shakhanbeh J (1988) Neurogenic inflammation in the skin of the rabbit. Agents Actions 25:228-230.

Magerl W, Szolcsányi J, Westerman RA, Handwerker HO (1987) Laser Doppler measurements of skin vasodilation elicited by percutaneous electrical stimulation of nociceptors in humans. Neurosci Lett 82:349-354.

Magerl W, Westerman RA, Mohner B, Handwerker HO (1990) Properties of transdermal histamine iontophoresis: differential effects of season, gender, and body region. I Invest Dermatol 94:347-352.

McMahon SB, Koltzenburg M (1992) Itching for an explanation. Trends Neurosci 15:497-501.

Melzack R, Wall PD (1965) Pain mechanisms: a new theory. Science 150:971-979.
Meyer RA, Campbell JN (1981) Myelinated nociceptive afferer.ts account for the hyperalgesia that follows a burn to the hand. Science 213:1527-1529.

Mountcastle VB (1984) Central nervous mechanisms in mechanoreceptive sensibility. In: Handbook of physiology, Sec 1, The nervous system, Vol III, Sensory processes, Pt 2 (Darian-Smith I, ed), pp 789878. Bethesda, MD: American Physiological Society.

Price DD (1988) Psychological and neural mechanisms of pain. New York: Raven

Price DD, Hu JW, Dubner R, Gracely RH (1977) Peripheral suppression of first pain and central summation of second pain evoked by noxious heat pulses. Pain 3:57-68.

Price DD, Hayes RL, Ruda MA, Dubner R (1978) Spatial and temporal transformation of input to spinothalamic tract neurons and their relation to somatic sensation. J Neurophysiol 41:933-947.

Reeh PW, Bayer J, Kocher L, Handwerker HO (1987) Sensitization of nociceptive cutaneous nerve fibers from the rat's tail by noxious mechanical stimulation. Exp Brain Res 65:505-512.

Robinson CJ, Torebjörk HE, LaMotte RH (1983) Psychophysical detection and pain ratings of incremental thermal stimuli: a comparison with nociceptor responses in humans. Brain Res 274:87-106.

Rusin KI, Ryu PD, Randic M (1992) Modulation of excitatory amino acid responses in rat dorsal horn neurons by tachykinins. J Neurophysiol 68:265-286.

Simone DA, Ngeow JY, Whitehouse J, Becerra Cabal L, Putterman GJ, LaMotte RH (1987) The magnitude and duration of itch produced by intracutaneous injections of histamine. Somatosens Res 5:81-92.

Simone DA, Baumann TK, LaMotte RH (1989) Dose-dependent pain and mechanical hyperalgesia in humans after intradermal injection of capsaicin. Pain 38:99-107.

Stevens SS (1975) Psychophysics: introduction to its perceptual, neural and social prospects. New York: Wiley.

Szolcsányi J (1984) Antidromic vasodilatation and neurogenic inflammation. In: Capsaicin and neurogenic inflammation: history and early findings (Chahl LA, Szolcsányi J, Lembeck F, eds), pp 7-25. Budapest: Akadámiai Kiadáo.

S7olcsányi J (1988) Antidromic vasodilatation and neurogenic inflammation. Agents Actions 23:4-11.

Thompson SWN, King AE, Woolf CJ (1990) Activity-dependent changes in rat ventral horn neurones in vitro: summation of prolonged afferent evoked postsynaptic depolarization produce a D-2-aminophosphonovaleric acid sensitive windup. Eur J Neurosci 2:638-649.

Torebjörk HE, LaMotte RH, Robinson CJ (1984) Peripheral neural correlates of magnitude of cutaneous pain and hyperalgesia: simultaneous recordings in humans of sensory judgments of pain and evoked responses in nociceptors with C-fibers. J Neurophysiol 51:325-339.

Treede R-D (1992) Vasodilator flare due to activation of superficial cutaneous afferents in humans: heat-sensitive versus histamine-sensitive fibers. Neurosci Lett 141:169-172.

Treede R-D, Meyer RA, Raja SN, Campbell JN (1992) Peripheral and central mechanisms of cutaneous hyperalgesia. Prog Neurobiol 38:397-421.

Urban L, Randić M (1984) Slow excitatory transmission in rat dorsal horn: possible mediation by peptides. Brain Res 290:336-341.

Vallbo ÅB, Hagbarth KE, Torebjörk HE, Wallin BG (1979) Somatosensory, proprioceptive, and sympathetic activity in human peripheral nerves. Physiol Rev 59:919-957.

Van Hees J, Gybels J (1981) C nociceptor activity in human nerve during painful and non painful skin stimulation. J Neurol Neurosurg Psychiatry 44:600-607.

Wall PD, Woolf CJ (1984) Muscle but not cutaneous C-afferent input produces prolonged increases in the excitability of the flexion reflex in the rat. J Physiol (Lond) 356:443-458.

Willis WD, Coggeshall RE (1991) Sensory function of the spinal cord, $2 d$ ed. New York: Plenum.

Woolf CJ (1992) Excitability changes in central neurons following peripheral damage: role of central sensitization in the pathogenesis of pain. In: Hyperalgesia and allodynia (Willis WD, ed), pp 221-243. New York: Raven 